DIGITALCOMMONS

$@$ WAYNESTATE-
Michigan Journal of Counseling:

Research, Theory and Practice

Volume 40 | Issue 1

Article 3

$6-1-2013$

\title{
The Impact of Adult Attention Deficit Hyperactivity Disorder Symptoms on Maternal Parenting Behaviors
}

Le'Ann L. Solmonson

Stephen F. Austin State University

Tiffany Stewart

Midwestern State University

Follow this and additional works at: https://digitalcommons.wayne.edu/mijoc

\section{Recommended Citation}

Solmonson, L. L., \& Stewart, T. (2013). The Impact of Adult Attention Deficit Hyperactivity Disorder Symptoms on Maternal Parenting Behaviors, Michigan Journal of Counseling, 40(1), 14-26. doi:10.22237/mijoc/1370044920

This Article is brought to you for free and open access by the Open Access Journals at DigitalCommons@WayneState. It has been accepted for inclusion in Michigan Journal of Counseling: Research, Theory and Practice by an authorized editor of DigitalCommons@WayneState. 


\title{
The Impact of Adult Attention Deficit Hyperactivity Disorder Symptoms on Maternal Parenting Behaviors
}

\author{
Le'Ann L. Solmonson \\ Stephen F. Austin State University
}

Tiffany Stewart

Midwestern State University

\begin{abstract}
The purpose of this qualitative research project is to examine the impact of maternal ADHD symptoms on managing the responsibilities related to parenting. The primary researcher conducted three interviews with mothers who exhibit ADHD symptoms in order to gain insight into their perceived difficulties related to the disorder. Analysis of the data indicates these mothers have difficulty completing tasks, are disorganized, and are easily overwhelmed with the responsibilities of parenting resulting in difficulty managing their own behavior and being consistent in disciplining their children. Due to these areas of deficiency, it is suggested the presence of maternal ADHD symptoms results in less than optimal parenting behaviors, which could result in negative outcomes for children.
\end{abstract}

Attention Deficit Hyperactivity Disorder is a condition that was once believed to only affect children. It was commonly believed that with further brain development and as hormonal or developmental changes occurred, most children would outgrow the condition during adolescence. However, during the last decade, research on the condition has established credibility and acceptance of the disorder in adults, and it is now recognized as a life long disorder (Elliott, 2002; Faraone \& Antshel, 2008; Young, 2002). A 2003 survey by the Attention Deficit Disorder Association (ADDA) indicates that approximately eight million adults suffer from the disorder, with the majority of the patients being undiagnosed.

The keystone features of Attention Deficit Hyperactivity Disorder (ADHD) are inattention, impulsivity, and hyperactivity (American Psychiatric Association, 2000). While these are not the only symptoms of ADHD, they are the ones that are utilized as specifiers in the Diagnostic and Statistical Manual of Mental Disorders 5 (APA, 2013). The symptoms of ADHD can result in impairment in several areas of the individual's life, including difficulty in organization,

Le'Ann Solmonson, Ph.D., LPC-S, CSC is an Associate Professor and Director of Counselor Education and Student Affairs Programs at Stephen F. Austin State University in Nacogdoches, Texas.

Tiffany Steward, Ph.D, LPC-Intern is an Assistant Professor at Midwestern State University in Wichita Fall, Texas. 
time management, task completion, and concentration. In addition, the individual may also suffer from low self-esteem, mood swings, increased frustration, academic or vocational failure, or lack of ambition (Waite, 2007). Individuals with ADHD are more at risk of developing secondary depression, anxiety, social phobias, eating disorders, substance abuse, and have increased health care utilization (Goodman, 2007; Taylor \& Keltner, 2002). Because these symptoms have been misunderstood in the past, individuals who suffer from ADHD may have been considered to be lazy or unmotivated, have low intelligence, or simply be a delinquent.

Over the past two decades, tremendous strides have been made in understanding ADHD, improving treatment options, and recognizing the presence of adult symptomology. Researchers have identified the prevalence of ADHD in the adult population to be roughly 3\%, despite gender (Faraone \& Biederman, 2005). However, the results from the previously referenced ADDA survey (2003) estimates that only about $25 \%$ of adults with ADHD are actually receiving treatment. Research findings (Faraone \& Biederman, 2005; Minde et al., 2003; Murphy \& Barkley, 1996; Murphy, Barkley, \& Bush, 2002) indicate that adults with ADHD have more academic concerns, family problems, marital breakups, a more unstable work record, more car accidents, and more interpersonal problems than non-ADHD adults. Adults with ADHD often have difficulty managing their own lives; yet, often do not discuss their difficulties (Elliott, 2002; McMillen, 2002; Waite, 2007; Young, 2002). So, what happens when the responsibility of parenting requires the management of others?

Inherent in the responsibilities of parenting is the ability to be attentive to the needs of a child. In addition, parenting calls for organization and structuring the life of a child (Weiss, Hechtman \& Weiss, 2000). The responsibility of parenting can be stressful for individuals without ADHD (Nadeau, 2004). The inability to effectively attend to parental obligations impacts child development negatively (Collins, Maccoby, Steinberg, Hetherington, \& Bornstein, 2000; Cunningham, 2007; Dwivedi \& Banhatti, 2005; Leverton, 2003). When combined with the psychopathology of ADHD, parenting behaviors can become dysfunctional. The presence of parental ADHD is a predictor for higher levels of family conflict and lesser levels of family cohesion (Biederman, Faraone, \& Monteaux, 2002). This same study suggests that non-ADHD children can suffer from ADHD-related dysfunction as a result of exposure to the ADHD parent, including a negative impact on school performance. ADHD symptoms can result in a more chaotic family environment and have a detrimental effect on children (Biederman, et al).

\section{Impact of ADHD on Women}

Several literature sources suggest that women report greater impact from ADHD symptoms than do men (Robison, et al, 2008; Additudemag.com, 2002; Seay, 2001). Robison, et al (2008) studied 515 adults with ADHD, of which thirty-four percent were women. The women reported higher levels of impairment on every measure that was administered. The measures included the Conners' Adult ADHD Rating Scale, the Wender-Reimherr Adult Attention Deficit Disorder Scale, the Hamilton Rating Scale for Anxiety, and the Hamilton 
Rating Scale for Depression. The women also reported higher levels of sleep disturbance, mood volatility, emotional over-reaction, and poor temper control. These same authors claim that previous statistics reporting a higher prevalence of ADHD in males is most likely due to the lack of detection of the disorder or misdiagnosis in females.

Nadeau (2004), a national recognized specialist in ADHD, identifies the additional stress women have in dealing with the demands of their daily life and ADHD. Nadeau describes the responsibility faced by women who are often the primary caretaker of the home and the family. It is a role that requires simultaneous functioning in multiple roles, with numerous interruptions, no imposed structure, and little support or encouragement. Mothers are frequently the scheduler, record keeper, and household manager of the family. Fathers may assist in household and parenting duties, but mothers are often the one to determine and direct what needs to be done. Many women hold these responsibilities while also working full time outside the home. The responsibility involved in the management of a household can be a source of stress. The additional expectations of the responsibilities involved in parenting can compound the level of stress experienced by mothers.

\section{ADHD and Parenting}

The tasks of parenting are synonymous with organization and management. Parents with ADHD report difficulty in organizing and managing their homes, their children, and their finances (Weiss \& Murray, 2003). In addition, Murray \& Johnston (2006) suggested these parents have shown a lower capacity to attend to child behavior. For an individual who is deficient in these areas, parenting may be another experience in failure. Abidin (1992) stated "...the richness or paucity of resources available naturally plays a role in the ultimate parenting behavior" (p. 410). He goes on to hypothesize that "parenting behavior and child adjustment are influenced by a number of sociological, environmental, behavioral, and developmental variables" (p.410). Abidin suggests a parenting model in which those variables influence the personality of the parent related to the parenting role. The parenting role is shaped through cognitions and beliefs related to self-expectations and the internal working model of self the parent has developed. In connecting this model to the research on adults with ADHD, the issues of low self-esteem, increased frustration, higher incidence of failure, and increased interpersonal problems, a parent with ADHD may perceive he or she has fewer resources available to assist in effective parenting and the associated responsibilities.

There is a significant amount of research indicating the specific parenting behaviors that are associated with positive and negative outcomes in children (Baumrind, 1966; Baumrind, 1996; Darling, 1999; Solmonson, 1993; Sonuga-Barke, Daley, \& Thompson, 2002). Research by McKee (2002) suggests that one of the strongest predictors of problematic parenting is parent psychopathology. Murray and Johnston (2006) found that ADHD behaviors in mothers' negatively impacted their ability to monitor the behavior of their children, which resulted in less consistency in their parenting. Due to symptoms of the disorder, ADHD parents are more likely to struggle with parenting behaviors associated 
with more positive outcomes that can have a significant influence on child development (Collins et al., 2000; Weiss, Hechtman, \& Weiss, 2000).

\section{Purpose and Significance of the Study}

The purpose of this study was to examine the impact of maternal ADHD symptoms on parenting behaviors. Given empirical evidence of Adult ADHD symptoms negatively impacting parenting behaviors, professional awareness will be increased to consider the inclusion of monitoring children for ADHDrelated dysfunction as a part of the treatment protocol of the ADHD parent. In addition, it will provide insight into the need for treatment compliance of ADHD parents in order to foster optimal developmental outcomes in children.

\section{Participants}

\section{Method}

Three mothers who consistently display symptoms of ADHD comprised the study sample. All three mothers were chosen through a purposeful sampling method. The mothers were identified through professional referrals after inquiries by the primary researcher. The ages of the mothers range from 36 to 48 . There are seven children among the three mothers, ranging in age from 4 to 17 . One of the mothers is a non-working mother, one works for a school district in a paraprofessional position, and the third is a teacher. All three are in the middle to upper income bracket. One of the mothers has a college degree. The other two have attended college, but did not receive a degree. Two of the mothers are professionally diagnosed and are receiving pharmacological treatment for the disorder. The third mother was not officially diagnosed with the disorder, but her symptoms were recognized after her youngest son was diagnosed with ADHD. This mother has not received professional treatment, but consults with the professional treating her son as a part of his treatment protocol.

\section{Research Design}

The use of qualitative inquiry was well suited for this study given that the purpose of phenomenology is to focus on the essence of the participants' personal experiences and to provide detailed description of it (Creswell, 2014). The analysis of this investigation was derivative based on the guidelines of Moustakas (1994), involving several components: collecting verbal exchanges that described the experience; examining transcripts carefully to get a sense of the whole; identifying statements of significance; eliminating irrelevant repetition; classify crucial themes; and integrating these meanings into a single description (Creswell, 2014).

The collection of verbal data from the selected participants began the process of exploring their lived experiences as related to their parenting struggles associated with the symptoms of ADHD. Literature can describe the symptoms of a disorder. However, an analysis of data gathered through the interviews offered a personal perspective on the essence of being a mother with 
ADHD and the difficulties associated with the disorder.

The interview questions were written by the primary researcher to gather data regarding the history of ADHD symptoms and treatment, educational experience, and impact on personal development. In addition, questions sought to provide the personal perspective of the individual in regards to difficulty in parenting. The interview questions were open-ended and developed in an attempt to prevent interviewer bias or manipulation. The content of the questions focused on the following topics: early indications of symptoms, identification and treatment history, educational experiences, developmental impact of symptoms (self-esteem, interpersonal relationships), job history and performance, historical and current struggles in personal management, historical and current struggles in household management, and struggles with parenting responsibilities. Professional peers reviewed the questions to ensure the focus on the symptoms of the disorder, as well as the behaviors that resulted as a manifestation of the symptoms. Data collection was done through an interview process. Each individual was interviewed individually in an agreed upon location. After an initial analysis of the data, two of the subjects were contacted for follow-up questions.

\section{Data Analysis}

The primary researcher reviewed the transcripts from the interviews and reduced them to significant statements and descriptions to determine categories for coding. This was done by carefully reading through the data and identifying statements of magnitude and/or shared experiences. Units of meaningful information were clustered together to create central themes. Completion of the analysis involved providing a description of the integration of participant experiences, textual descriptions, and individual structural descriptions (Creswell, 1998; Creswell, Hanson, Clark, \& Morales, 2007). Due to previous research that provides information regarding ADHD symptomology, the manifestation of those symptoms in parenting behaviors was the focus on the research. Preliminary analysis of the data looked for commonalities in the overall experience of the individuals, rather than on focusing on the subject of parenting. Once an understanding of the experience of the disorder was garnered, the impact on parenting behaviors was examined.

The categories of coding were determined by the primary researcher based upon research questions including managerial responsibilities, management of own behavior, and management of the behavior of children. Specific coding categories included diagnosis, treatment, effects of treatment, symptomology, coping skills, school experiences, impact on development, work experience, management of self, management of children, management of household, management of parenting responsibilities, dealing with ADHD in their child, and behavioral observations during the interview. The information was categorized into early experiences, description of symptoms, treatment, coping skills, management of the home and family, management of self, impact on parenting, family response to symptoms, and having a child with ADHD.

Trustworthiness in qualitative research is key in determining accuracy (Creswell \& Miller, 2000). Validity checks were used throughout the process of the study so that integrity of the findings remained consistent. Because the 
questions were asking subjects to describe their personal experiences, the responses were descriptive in nature. Using three subjects provided for investigator triangulation to determine if the experiences of the mothers were similar.

\section{Results and Discussion}

Abidin (1992) suggests a parenting model in which personal variables influence the personality of the parent related to the parenting role. That personality is developed based upon experiences early in life. Knowledge related to the overall development of the three mothers assists in understanding the shaping of their personalities. The parenting role is shaped through cognitions and beliefs related to self-expectations and the internal working model of self. The symptoms of ADHD result in behaviors that are likely to influence an individual's sense of self as identified in the interviews with the mothers.

\section{Early experiences}

All three subjects described early experiences with learning difficulties and an awareness that they were different from peers. None of the subjects understood the symptoms of ADHD until they reached adulthood, and could not understand the reason for their struggles. All three also identified a negative impact of their early struggles on their self-esteem. All three described themselves as very social and enjoying being around people. All three also laughed and joked about the struggles they have experienced. Only one of the mothers identified her jovial nature as developing in order to divert attention from her perceived inadequacies.

\section{Description of symptoms}

There were common descriptions of the experience with ADHD symptoms. All three described difficulty with task completion, being disorganized, and easily distracted or sidetracked. In addition, all three discussed being forgetful and frequently being late. Feeling overwhelmed is a common occurrence among the women. One also described increased feelings of anxiety, and one mother deals with depression related to the disorder. However, although she labeled her symptoms as depression, her description was more synonymous with anxiety.

During the interviews, two of the mothers displayed hyperactive symptoms. The researchers also observed distractibility and disorganized thoughts during the interview. All three tended to deviate from the question being asked, but two of the mothers were very difficult to keep focused. They would begin to answer the question and then switch to another topic. They may or may not return to the question without redirection.

All three mothers also discussed being very easily bored. They had all three changed jobs frequently until they found a position that offered variety in 
daily tasks. Jobs that required routine or involved repetition of mundane tasks were unsatisfying, and they looked for something that provided a daily challenge. None of the three had been successful in desk jobs.

\section{Treatment}

Only two of the mothers are currently being treated for ADHD, and both take Adderall. They agreed that medication has made a tremendous difference in their functioning and has improved their quality of life. One mother describes being able to sit still and relax while reading to her children. Prior to medication, this was difficult for her and she could not enjoy it due to focusing on other things she should be doing. Both stated they are able to get tasks accomplished and feel less overwhelmed by daily demands.

\section{Coping Skills}

In order to manage the symptoms of ADHD, each of the mothers uses coping skills they have learned to assist in being more successful in completion of daily tasks. All three stated they must use some kind of a list in order to remember what needs to be done. Two of the mothers use a calendar and keep it with them at all times. The oldest mother uses sticky notes that she puts on her clothing when she leaves the house in order to remember errands she needs to run. She also uses sticky notes in her home. Two of the mothers talked about having to plan things in advance. The youngest mother is obsessive about planning, to the point that she is often unable to relax because she is constantly going over in her head what needs to be done. She does this out of fear of forgetting. Hyper-focusing was also a common method of task completion. One mother described not allowing herself to think about anything else because of a fear of not finishing something. As a result, she often forgot other things, including meetings, appointments, and picking up her children from activities. This same mother acknowledged the negative coping skill of avoidance when tasks seem too large and she becomes overwhelmed.

\section{Management of Home and Family}

Research indicates that many adult women who suffer from ADHD have a difficult time managing their home and related responsibilities (Taylor \& Keltner, 2002). All three of the mothers interviewed supported this in their own personal experiences. They described household tasks as overwhelming and difficult to complete. It was common to spend a significant amount of time working, but see little progress from their efforts. They described beginning one task and being distracted by another. They often would start several tasks and not get anything completed. They also described their homes as unorganized. One of the mothers will only allow very close friends and family into her home because the clutter in her home embarrasses her. The youngest mother has a nanny who takes care of all household tasks because she was unable to manage it without help. 
Two of the mothers stated they have difficulty establishing a routine, which they realize is difficult for their children. The third mother stated that she works very hard to maintain a routine because she realizes how important it is for her children. The oldest mother describes years of struggling to maintain her home because of her symptoms. She has recently found a website that has provided information on household management for women with ADHD. By utilizing the ideas and skills on the website, she has found it much easier to manage her home.

\section{Management of self}

Due to symptoms of impulsivity, it would be expected that an individual might struggle to maintain composure in times of stress. All three mothers supported this theory. They described being easily frustrated or angered when dealing with stressful situations, especially in regards to their children. One mother described feeling out of control and having to apologize to her children for things she has said. Two of the mothers were aware that when they become frustrated with themselves, they take it out on their children.

\section{Impact on Parenting}

All three mothers also supported research indicating the symptoms of ADHD impact their parenting behaviors. Two of the mothers described difficulty being consistent with their children, not only in disciplining, but also in establishing routines for them. The youngest mother realizes that she is impatient with her children and less tolerant of misbehavior.

They recognize that forgetting and being late also impacts their children. One mother admitted that she has forgotten to pick up her children on numerous occasions. She has also forgotten to do things she has told her children she would do. She described a recent situation in which she forgot to give her son lunch money, and even after he called her from school to remind her, she forgot again. He missed half of his lunch period waiting for her in the school office and had to make a second phone call to remind her. She stated that she frequently get calls from her children asking where she is because she has forgotten to pick them up or is late. She has given each of her children a cell phone so that they will be able to call her when she forgets. This same mother stated that she will discipline her children by removing privileges, and then forget and give them permission to do something from which they have been grounded.

All three expressed a true enjoyment from the experience of motherhood. When asked what they most enjoyed about being a parent, all three gave the same reply. They enjoy their children and who they are as individuals. They all stated they enjoy spending time with and participating in activities with their children. One mother finds it hard to interrupt activities they are enjoying in order to take care of other tasks. This contributes to being late to other commitments, not getting household tasks completed, or dinner being late. 


\section{Family Response to Symptoms}

It would stand to reason that family members might be impacted by the symptoms of the disorder. Two of the mothers recognize their family's frustration as a result of their symptoms. They discussed their spouse being intolerant or frustrated at times, as well as their children. The mother with the oldest child has been criticized by her son for not being consistent in dealing with both children. He believes it is unfair when both boys are not held to the same standards. The youngest mother is divorced and believes her symptoms contributed to her divorce. She does not see the same level of distress in her children as described by the other two mothers. However, her children are only 4 and 6 years old, which she attributes to the difference reported by the mothers of the older children.

\section{Children with ADHD}

Due to the research regarding the genetic impact of the disorder, it would be predicted that ADHD would be present among the seven children. Each of the mothers has one child that has been diagnosed and is being treated. Two of the mothers recognized her own symptoms after her child was diagnosed. All three expressed a fear of their child repeating their own personal history of struggling. The fear was evident as two of the mothers became tearful when discussing this subject. They also acknowledged being sympathetic and understanding the difficulties experienced by the children. Two of the mothers become frustrated in trying to help their child because they do not feel as if they are able to manage their own disorder. The youngest mother articulated the most beneficial coping skills in managing her own symptoms and believes she is able to help her child begin to develop those same skills.

\section{Conclusions}

The purpose of this study was to examine the impact of Adult ADHD symptoms on parenting behaviors. The results of this study clearly indicate that mothers with ADHD have a difficult time in managing the responsibilities associated with parenting. The difficulties are in the area of household management, controlling their own behavior, and being consistent in dealing with their children. The development of coping skills to manage symptoms of the disorder appears to have a positive impact; however, the subjects perceive they still struggle more than mothers without ADHD. Their perception is that mothers without ADHD are naturally able to do the things that ADHD mothers have to work hard to accomplish. All three mothers have the perception that their disorder has a detrimental impact on their children.

Researchers indicate that establishing a routine and being consistent results in more positive outcomes in children (Baumrind, 1966; Baumrind, 1996; Darling, 1999; Solmonson, 1993). All three mothers identified having difficulty in these areas. In addition, being late and forgetful was also an issue. These areas of deficiency may result in the children being unable to feel secure that their mother will be reliable and consistent. Solmonson (1993) concluded that even 
when parenting behaviors were less desirable, if there was consistency in the parenting style, children were more likely to exhibit positive behavioral traits. Given the identified struggles of the subjects, it would appear that the symptoms of ADHD result in less than optimal parenting behaviors. Replication of this study with a larger, more diverse population would allow for a better understanding of the struggles of mothers with ADHD and the ability to generalize the results.

\section{Implications for Practice and Future Research}

The increased understanding of the difficulties involved in parenting for mothers with ADHD has several implications for treating the disorder. The two mothers who are receiving pharmacotherapy both indicated a reduction in symptoms while medicated. This would offer support for the need for medication compliance as a component of managing the disorder. In addition, all three mothers discussed learning skills and behaviors that minimize the impact of their symptoms. Behavioral therapy and psychoeducational work is warranted to assist individuals in managing their symptoms. Monitoring children for indications of ADHD-related dysfunction is also warranted. In addition, educating mothers with ADHD about parenting behaviors that result in positive outcomes in their children may result in increased motivation to actively engage in therapeutic interventions.

Further research in this area is warranted to generalize the findings to a larger population. It would also be interesting to investigate the impact of the non-ADHD parent in maintaining stability in the home. In addition, research is needed to determine how the presence of ADHD among fathers might impact children. Research conducted on the perception of the children of ADHD parents would also increase the level of knowledge in regards to the impact of paternal ADHD symptoms on children. In order to establish evidence-based practices, research that focused on interventions would also be useful. Some of those interventions would include a comparison of the effectiveness of medication only, psychoeducational skills training only, and a combined approach. Investigating the impact of group work would provide information related to the impact of a homogeneous support group on fostering positive parenting behaviors. Whereas a significant amount of research is available on the subject of Adult ADHD, more research is needed to study the possibility of secondary impact of the disorder on children of ADHD parents.

\section{References}

Abidin, R. R. (1992). The determinants of parenting behavior. Journal of Clinical Child Psychology, 21(4), 407-412.

American Psychiatric Association (2000). Diagnostic and statistical manual, fourth edition, text revision. Washington, DC: American Psychiatric Association.

American Psychiatric Association (2013). Diagnostic and statistical manual, fifth edition. Washington, DC: American Psychiatric Association. 
Additudemag.com (2002, August 19). Nationwide survey of more than 3,000 people uncovers gender differences in $A D H D$. Retrieved from http:// www.additudemag.com/selfhelp.asp?DEPT_NO=406\&SUB_NO=4 Attention Deficit Disorder Association (2003, June 25). Survey reveäls adult $A D H D$ often undiagnosed by primary care physicians. Retrieved from http://www.add.org/survey.html

Baumrind, D. (1966). Effects of authoritative parental control on child behavior.

Child Development, 37(4), 887-907.

Baumrind, D. (1996). The discipline controversy revisited. Family Relations, 45 (4), 405-414.

Biederman, J., Faraone, S. V., \& Monteaux, M. C. (2002). Impact of exposure to parental Attention Deficit Hyperactivity Disorder on clinical features and dysfunction of offspring. Psychological Medicine, 32, 817-827.

Collins, W. A., Maccoby, E. E., Steinberg, L., Hetherington, E. M., \& Bornstein, M. H. (2000). Contemporary research on parenting: The case for nature and nurture. American Psychologist, 55, 218-232.

Creswell, J. W. (1998). Qualitative inquiry and research design: Choosing among five traditions. Thousand Oaks, CA: Sage.

Creswell, J. W. (2014). Research design: Qualitative, quantitative, and mixed methods approaches. Thousand Oaks, CA: Sage.

Creswell, J. W., Hanson, W. E., Clark, V. L., \& Morales, A. (2007). Qualitative research designs: Selection and implementation. The Counseling Psychologist, 35, 236-264. Doi:10.1177/00111116287390

Creswell, J. W., \& Miller, D. (2000). Determining validity in qualitative inquiry. Theory Into Practice, 39(3), 124-130.

Cunningham, C. (2007). A family-centered approach to planning and measuring the outcome of intervention for children with attention-deficit/

hyperactivity disorder. Journal of Pediatric Psychology, 32(6), 676-694. Doi:101093/jpepsy/jsm021

Darling, N. (1999). Parenting styles and its correlates (report No. EDO-PS-993). Champaign, IL: Office of Educational Research and Improvement (ERIC Document Reproduction Service No. ED427896)

Dwivedi, K., \& Banhattii, R. (2005). Attention deficit/hyperactivity disorder and ethnicity. Archives of Disease in Childhood, 90, 10-12. doi:10.1136/ adc. 2004.058180

Elliott, H. (2002). Attention deficit hyperactivity disorders in adults: A guide for the primary care physician [Electronic version]. Southern Medical Journal, 95(7), 736-742.

Faraone, S. V., \& Antshel, K. (2008). Diagnosing and treating attention-deficit/ hyperactivity disorder in adults. World Psychiatry, 7(3), 131-136.

Faraone, S. V., \& Biederman, J. (2005). What is the prevalence of adult ADHD? Results of a population screen of 966 adults. Journal of Attention Disorders, 9, 384-391.

Goodman, D. (2007). The consequences of Attention-Deficit Hyperactivity Disorders in adults. Journal of Psychiatric Practice, 13(5) 318-327.

Leverton, T. (2003). Parental psychiatric illness: The implications for children. Current Opinion in Psychiatry, 16(4), 395-402. 
McMillen, M. F. (2002). Focusing on ADD in the workplace: Attention Deficit Hyperactivity Disorder affects adults and could hinder productivity in the workplace if not diagnosed and treated properly [Electronic version]. HR Magazine, 47 (12), 56-61.

Minde, K., Eakin, L., Hechtman, L., Ochs, E., Bouffard, R., \& Greenfield, B., et al. (2003). The psychosocial functioning of children and spouses of adults with ADHD. Journal of Child Psychology and Psychiatry, 44, 637646.

Moustakas, C. (1994). Phenomenological research methods. Thousand Oaks, CA: Sage.

Murray, C. \& Johnston, C. (2006). Parenting in mothers with and without attention-deficit/ hyperactivity disorder. Journal of Abnormal Psychology, 115 (1), 52-61. DOI: 10.1037/0021-843X.115.1.52.

Murphy, K. \& Barkley, R. A. (1996). Attention deficit hyperactivity disorder in adults: Comorbidities and adaptive impairments. Comprehensive Psychiatry, 37, 393-401.

Murphy, K. R., Barkley, R. A., \& Bush, T. (2002). Young adults with attention deficit hyperactivity disorder: Subtype differences in comorbidity, educational, and clinical history. The Journal of Nervous and Mental Disease, 190, 147-157.

Nadeau, K. G. (2004). Feeling overwhelmed, disorganized, scattered? Retrieved from www.insightpsychological.com/Library/Women\%20and\% 20ADHD.doc

Robison, R. J., Reimherr, F. W., Marchant, B. K., Faraone, S. V., Adler, L. A., \& West, S. A. (2008). Gender differences in 2 clinical trials of adults with Attention-Deficity/Hyperactivity Disorder: A retrospective data analysis. Journal of Clincial Psychiatry, 69 (2), 213-221.

Seay, B. (2001). Higher IQ, depression may indicate $A D / H D$ in teenage girls. Retrieved from http://www.additudemag.com/selfhelp.asp?

DEPT_NO=301\&ARTICLE_NO=16\&ARCV $=1$

Solmonson, L. (1993). Parental use of reasoning and children with exceptional classroom behavior. Unpublished master's thesis, University of Texas at the Permian Basin, Odessa, TX.

Sonuga-Barke, E. Daley, D., \& Thompson, M. (2002). Does maternal ADHD reduce the effectiveness of parent training for preschool children's ADHD? Journal of the American Academy of Child and Adolescent Psychiatry, 41, 696-702.

Taylor, E. W. \& Keltner, N. L. (2002). Messy purse girls: Adult females and ADHD. Perspectives in Psychiatric Care, 38(2), 69-72.

Waite, R. (2007). Women and attention deficit disorder: A great burden overlooked. Journal of the American Academy of Nurse Practitioners, 19(3), 116-125.

Weiss, M., Hechtman, L., \& Weiss. G. (2000) ADHD in parents [Electronic version). Journal of the American Academy of Child and Adolescent Psychiatry, 39(8), 1059. 
Weiss, M. \& Murray, C. (2003). Assessment and management of attentiondeficit hyperactiviy disorder in adults [Electronic version). Canadian Medical Association Journal, 168(6), 715-722.

Young, J. L. (2002). Recognition is growing of its possible role in adult psychiatric symptoms. (ADHD in adults: Contemporary approaches) [Electronic version]. Behavioral Health Management, 22(3), 21-25. 